\title{
BMJ open Vitamin C may alleviate exercise-induced
bronchoconstriction: a meta-analysis
}

\author{
Harri Hemilä
}

To cite: Hemilä H. Vitamin C may alleviate exercise-induced bronchoconstriction: a metaanalysis. BMJ Open 2013;3: e002416. doi:10.1136/ bmjopen-2012-002416 additional material for this paper is available online. To view these files please visit the journal online (http://dx.doi.org/10.1136/ bmjopen-2012-002416).

Received 27 November 2012 Revised 16 May 2013 Accepted 17 May 2013

This final article is available for use under the terms of the Creative Commons Attribution Non-Commercial 2.0 Licence; see http://bmjopen.bmj.com
- Prepublication history and

\section{ABSTRACT}

Objective: To determine whether vitamin C administration influences exercise-induced bronchoconstriction (EIB).

Design: Systematic review and meta-analysis. Methods: MEDLINE and Scopus were searched for placebo-controlled trials on vitamin $\mathrm{C}$ and EIB. The primary measures of vitamin $C$ effect used in this study were: (1) the arithmetic difference and (2) the relative effect in the postexercise forced expiratory volume in $1 \mathrm{~s}\left(\mathrm{FEV}_{1}\right)$ decline between the vitamin $\mathrm{C}$ and placebo periods. The relative effect of vitamin $C$ administration on $\mathrm{FEV}_{1}$ was analysed by using linear modelling for two studies that reported full or partial individual-level data. The arithmetic differences and the relative effects were pooled by the inverse variance method. A secondary measure of the vitamin $C$ effect was the difference in the proportion of participants suffering from EIB on the vitamin $C$ and placebo days.

Results: 3 placebo-controlled trials that studied the effect of vitamin C on ElB were identified. In all, they had 40 participants. The pooled effect estimate indicated a reduction of 8.4 percentage points $(95 \% \mathrm{Cl}$ 4.6 to 12) in the postexercise $\mathrm{FEV}_{1}$ decline when vitamin $\mathrm{C}$ was administered before exercise. The pooled relative effect estimate indicated a $48 \%$ reduction $(95 \% \mathrm{Cl} 33 \%$ to $64 \%)$ in the postexercise $\mathrm{FEV}_{1}$ decline when vitamin $\mathrm{C}$ was administered before exercise. One study needed imputations to include it in the meta-analyses, but it also reported that vitamin C decreased the proportion of participants who suffered from EIB by 50 percentage points ( $95 \% \mathrm{Cl} 23$ to 68$)$; this comparison did not need data imputations.

Conclusions: Given the safety and low cost of vitamin $\mathrm{C}$, and the positive findings for vitamin C administration in the three EIB studies, it seems reasonable for physically active people to test vitamin C when they have respiratory symptoms such as cough associated with exercise. Further research on the effects of vitamin C on EIB is warranted.

\section{INTRODUCTION}

Department of Public Health, University of Helsinki, Helsinki, Finland

Correspondence to Dr Harri Hemilä; harri.hemila@helsinki.fi
Exercise-induced bronchoconstriction (EIB) is a transient narrowing of the airways that occurs during or after exercise. Usually, a $10 \%$ or greater exercise-induced decline in forced expiratory volume in $1 \mathrm{~s}\left(\mathrm{FEV}_{1}\right)$ is classified as EIB. ${ }^{1}$ The prevalence of EIB varies

\section{ARTICLE SUMMARY}

\section{Article focus}

- Exercise causes airway narrowing in about $10 \%$ of the general population and in up to $50 \%$ of competitive athletes.

- Laboratory studies have indicated that vitamin C may have an alleviating influence on bronchoconstriction.

- The aim of this research was to examine whether vitamin C administration influences forced expiratory volume in $1 \mathrm{~s}\left(\mathrm{FEV}_{1}\right)$ decline caused by exercise.

\section{Key messages}

- Vitamin C may alleviate respiratory symptoms caused by exercise.

- In future studies, linear modelling should be used to examine the effect of vitamin $C$ on the postexercise $\mathrm{FEV}_{1}$ decline instead of calculating the mean effect of vitamin $C$ on the postexercise $\mathrm{FEV}_{1}$ decline.

Strengths and limitations of this study

- The included studies were methodologically satisfactory and their results were consistent and close.

- The included studies were small with 40 participants in all.

from about $10 \%$ in the general population to about $50 \%$ in some fields of competitive athletics. ${ }^{1}$ The pathophysiology of EIB is not well understood. However, respiratory water loss leads to the release of inflammatory mediators, such as histamine, leukotrienes (LTs) and prostaglandins (PGs), all of which can cause bronchoconstriction. ${ }^{12}$ Increased levels of exhaled nitric oxide have also been associated with EIB. ${ }^{3}$

There is evidence that vitamin $\mathrm{C}$ plays a role in lung function. The production of various prostanoids in lung tissues is influenced by vitamin $\mathrm{C}$, and vitamin $\mathrm{C}$ deficiency increases the level of bronchoconstrictor $\mathrm{PGF}_{2 \alpha}{ }^{4-6}$ An increase in airway hyperresponsiveness to histamine, which was further enhanced by indomethacin administration, was observed in guinea pigs on a diet deficient in vitamin $\mathrm{C}^{6}{ }^{6}$ In isolated guinea 
pig trachea smooth muscle, vitamin $\mathrm{C}$ decreased the contractions caused by $\mathrm{PGF}_{2 \alpha}$, histamine and carbamylcholine. ${ }^{4} 78$ Indomethacin antagonised the effect of vitamin $\mathrm{C}$ on chemically induced bronchoconstriction in humans ${ }^{9} 10$ and the effect of vitamin $\mathrm{C}$ on the contractions of guinea pig tracheal muscle. ${ }^{8}$ Thus, the effects of vitamin $\mathrm{C}$ might be partly mediated by alterations in PG metabolism. In humans, a 2-week vitamin C (1.5 g/day) administration regime reduced the postexercise increase in the urinary markers for the bronchoconstrictors $\mathrm{LTC}_{4}-\mathrm{LTE}_{4}$ and $\mathrm{PGD}_{2}$, in addition to reducing the increase in exhaled nitric oxide. ${ }^{11}$

Heavy physical exertion generates oxidative stress, and therefore, as an antioxidant, the effects of vitamin C might be more manifest in people doing exercise. ${ }^{12} 13$ The importance of vitamin $\mathrm{C}$ on the respiratory system is also indicated by the decrease in the incidence of the common cold in people under heavy acute physical stress $^{1415}$ and by its effects on the severity of the upper and lower respiratory tract infections. ${ }^{15-17}$

Previously, a systematic review examined the effect of vitamin $\mathrm{C}$ on EIB. ${ }^{18}$ However, there were substantial errors in the extraction of data and data analysis in that review. ${ }^{19}$ The purpose of this systematic review is to examine whether vitamin $\mathrm{C}$ administration influences the postexercise $\mathrm{FEV}_{1}$ decline.

\section{METHODS}

\section{Types of studies}

Controlled trials, both randomised and non-randomised, were included in this systematic review. Only placebocontrolled blinded trials were included as the severity of EIB might be affected by the patients' awareness of the treatment. Studies that used children and adults of either gender and any age were considered eligible.

\section{Types of interventions}

The intervention considered was oral or intravenous administration of vitamin $\mathrm{C}$ (ascorbic acid or its salts) of at least $0.2 \mathrm{~g}$ daily for a single day or for a more extended period. The dose limit was set as a pragmatic choice. When a trial with a low dose gives a negative result, the negative findings can be attributed to that low dosage. Thus, trials with large doses are more critical for testing whether vitamin $\mathrm{C}$ is effective in influencing EIB.

\section{The outcomes and the measure of the vitamin $\mathrm{C}$ effect}

The primary outcome in this meta-analysis is the relative $\mathrm{FEV}_{1}$ decline caused by exercise (as a percentage). The measures selected for the vitamin $\mathrm{C}$ effect were: (1) the arithmetic difference in the postexercise decline of $\mathrm{FEV}_{1}$ between the placebo and vitamin $\mathrm{C}$ periods; this is called the percentage point difference and (2) the relative effect in the decline of postexercise $\mathrm{FEV}_{1}$ between the vitamin $\mathrm{C}$ and placebo periods. A secondary outcome in this meta-analysis was the proportion of participants who suffered from EIB after the exercise test, and the measure of vitamin $\mathrm{C}$ effect was taken as the difference in the occurrence in EIB between the vitamin $\mathrm{C}$ and placebo days.

\section{Literature searches}

MEDLINE (OVID) was searched using the Medical Subject Headings (MeSH) terms 'ascorbic acid' and 'exercise-induced asthma'. A similar search was carried out in Scopus. No language restrictions were used. The databases were searched from their inception to February 2013. The reference lists of identified studies and review articles were screened for additional references. See online supplementary file 1 for the flow diagram of the literature search.

\section{Selection of studies and data extraction}

Five controlled trials that report on vitamin $\mathrm{C}$ and EIB were identified. Three of them satisfied the selection criteria (table 1). One of the studies that was not included was not placebo controlled ${ }^{22}$ and the other studied the combination of vitamins $\mathrm{C}$ and $\mathrm{E} .{ }^{23}$ The data of the three included trials were extracted and analysed. The original study authors were contacted when appropriate in order to obtain further data.

Schachter and Schlesinger ${ }^{20}$ reported the individual-level $\mathrm{FEV}_{1}$ measurements for a 12-participant crossover study. The decline in $\mathrm{FEV}_{1}$ caused by exercise was calculated in this present study (see online supplementary file 2).

Tecklenburg $e t a l^{11}$ reported the mean decline in postexercise $\mathrm{FEV}_{1}$ for the vitamin $\mathrm{C}$ and placebo phases of an eight-participant crossover study. However, these authors did not report the paired SD value for the mean difference between the two phases. Dr Tecklenburg was subsequently contacted, and she kindly sent the paired $\mathrm{SD}$ value for the mean difference in decline of the postexercise $\mathrm{FEV}_{1}$ (see online supplementary file 2).

Cohen et $a l^{21}$ reported $\mathrm{FEV}_{1}$ values before and after exercise in only 11 of the 20 participants of a crossover study. These 11 had been selected because of the disappearance of EIB during the study. Thus, the difference in the postexercise $\mathrm{FEV}_{1}$ decline between the vitamin $\mathrm{C}$ and placebo days can be calculated for these 11 participants (the mean vitamin $\mathrm{C}$ effect was a reduction of 20.4 percentage points in the postexercise decline in $\mathrm{FEV}_{1}$ ). Dr Cohen was contacted, but he no longer retained those data. Therefore, to include the Cohen et al trial in this meta-analysis, the $\mathrm{FEV}_{1}$ values for the remaining nine participants had to be imputed. A conservative 'no vitamin C effect' estimate was imputed for all the nine participants with missing data (see online supplementary file 2). As a sensitivity analysis, the Cohen et al study was excluded from the meta-analysis in figure 1 to examine whether its exclusion influenced the conclusions.

Cohen $e t$ al also reported the number of participants who suffered from EIB after the exercise test. This outcome did not require imputations and it was used as a secondary outcome for comparing the vitamin $\mathrm{C}$ and placebo days in the Cohen study. 
Table 1 Trials on vitamin C supplementation and exercise-induced bronchoconstriction

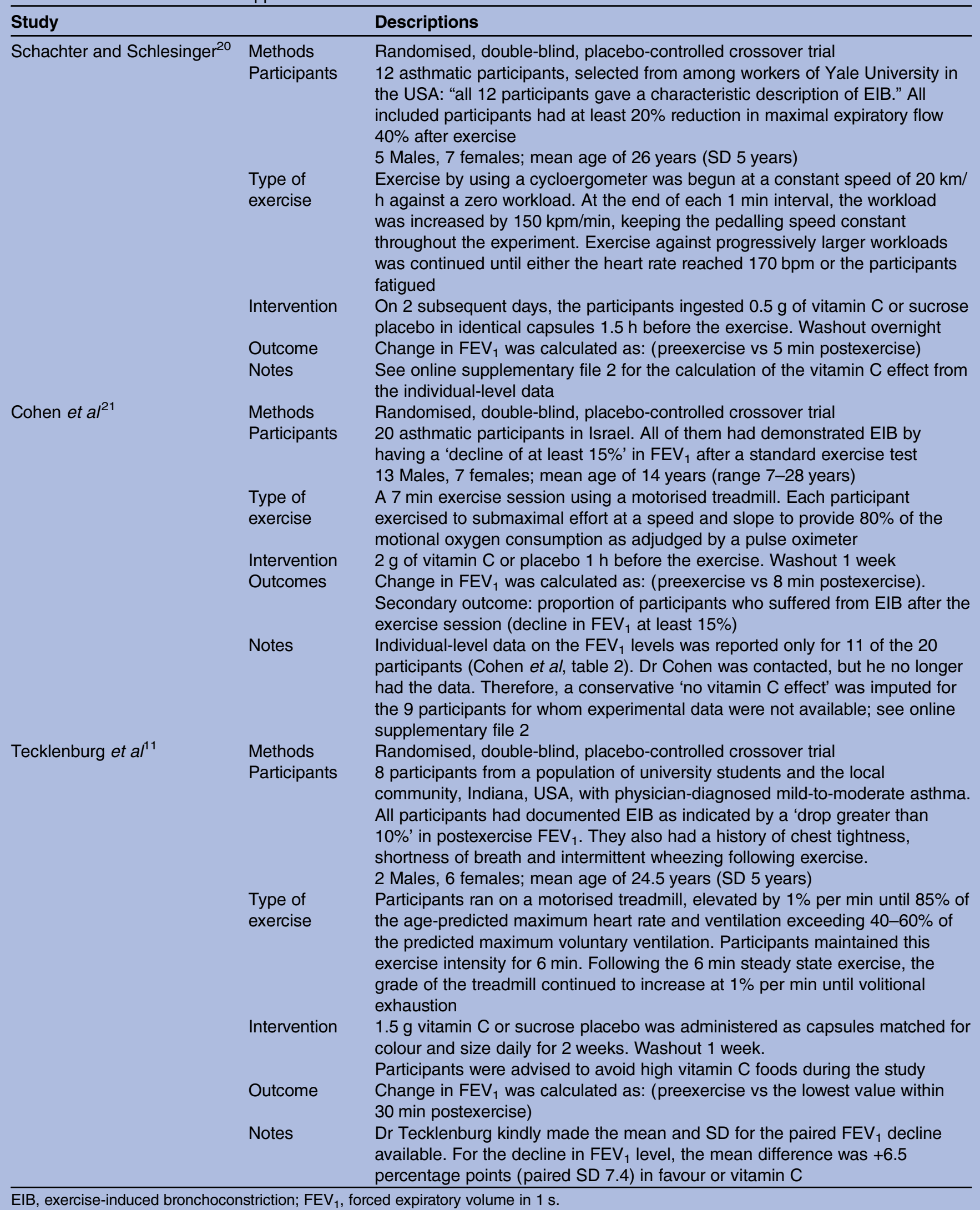

Statistical analysis

The statistical heterogeneity of the three studies was assessed by using the $\chi^{2}$ test and the $\mathrm{I}^{2}$ index. ${ }^{24}$ The latter examines the percentage of total variation across studies that is due to heterogeneity between studies rather than by randomness. A value of $\mathrm{I}^{2}$ greater than 
Study

Tecklenburg 2007
Schachter 1982
Cohen 1997

Fixed effect model
TE seTE

$95 \%-\mathrm{Cl} W($ fixed)

$\begin{array}{rr}6.50 & 3.16 \\ 7.38 & 3.83 \\ 11.20 & 3.24\end{array}$

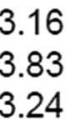

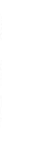
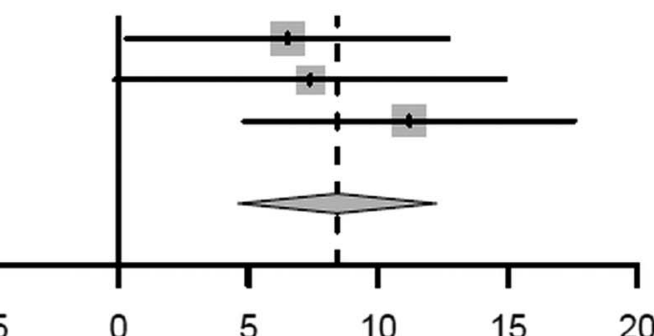

$\begin{array}{llllll}-5 & 0 & 5 & 10 & 15 & 20\end{array}$

Effect of vitamin C on FEV1 decline (percentage points)
$6.50 \quad[0.31 ; 12.69] \quad 38.0 \%$

$7.38 \quad[-0.13 ; 14.89] \quad 25.9 \%$

$11.20 \quad[4.85 ; 17.55] \quad 36.1 \%$

$8.43[4.61 ; 12.24] 100 \%$

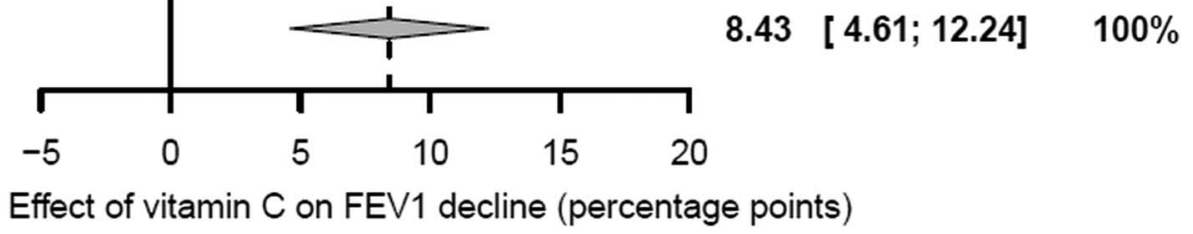

Figure 1 Percentage point effect of vitamin $\mathrm{C}$ on the decline in $\mathrm{FEV}_{1}$ caused by exercise. The horizontal lines indicate the $95 \%$ $\mathrm{Cl}$ for the three trials and the squares in the middle of the lines indicate the mean effect of the study. The diamond shape at the bottom indicates the $95 \% \mathrm{Cl}$ for the pooled effect. $\mathrm{FEV}_{1}$, forced expiratory volume in $1 \mathrm{~s}$; seTE, SE of TE; TE, treatment effect; W, weight of the study.

about $70 \%$ indicates a high level of heterogeneity. Since the three identified trials showed no statistical heterogeneity, their results were pooled using the inverse variance method assuming a fixed effect by running the program 'metagen' of the R package (see online supplementary file 2 for details of the calculations). ${ }^{25}$ The program 'forest.meta' of the $\mathrm{R}$ package was used to construct the forest plots.

To examine the relative effect of vitamin $\mathrm{C}$ on the postexercise $\mathrm{FEV}_{1}$ decline, the vitamin $\mathrm{C}$ effect was modelled using the placebo-day postexercise $\mathrm{FEV}_{1}$ decline as the explanatory variable, by using the linear model "lm" program of the $\mathrm{R}$ package. ${ }^{25}$ To test whether the addition of the placebo-day postexercise $\mathrm{FEV}_{1}$ decline values significantly improves the linear model fit, the model containing the placebo-day $\mathrm{FEV}_{1}$ decline values was compared with the model without them. The improvement of the model fit was calculated from the change in $-2 \times \log$ (likelihood), which follows the $\chi^{2}(1 \mathrm{df})$ distribution.

To study the effect of vitamin $\mathrm{C}$ on the proportion of participants who suffered from EIB in the Cohen et al study, the mid $\mathrm{p}$ value was calculated ${ }^{26}$ and the $95 \%$ CI was calculated by using the Agresti-Caffo method. ${ }^{27}$

The two-tailed $\mathrm{p}$ values are presented in this text.

\section{RESULTS}

Three randomised, placebo-controlled, double-blind crossover trials that had examined the effect of vitamin $\mathrm{C}$ supplementation on the decline in $\mathrm{FEV}_{1}$ caused by exercise were retrieved. Double-blind means that all studies used allocation concealment, although the term was not used. The experimental conditions were similar (table 1). The three trials had a total of 40 participants. There was no statistical heterogeneity found between the three studies for the percentage points scale: $\mathrm{I}^{2}=0 \% ; \chi^{2}(2 \mathrm{df})=1.1 ; \mathrm{p}=0.5$. Therefore, the pooled percentage point estimate of the vitamin $\mathrm{C}$ effect was calculated (figure 1). Compared with the placebo phases, the mean reduction in the postexercise $\mathrm{FEV}_{1}$ decline was 8.4 percentage points during the vitamin $\mathrm{C}$ phases (95\% CI 4.6 to 12.2; $\mathrm{p}<0.001)$.
In the Schachter and Schlesinger ${ }^{20}$ study, the postexercise $\mathrm{FEV}_{1}$ decline was $17.6 \%$ for placebo, but only $10.2 \%$ for vitamin $\mathrm{C}$ ( $0.5 \mathrm{~g}$ single dose), with a 7.4 percentage point $(95 \%$ CI -0.1 to $14.9 ; \mathrm{p}=0.054)$ improvement for the vitamin $\mathrm{C}$ treatment. In the Tecklenburg et $a l^{11}$ study, the postexercise $\mathrm{FEV}_{1}$ decline was $12.9 \%$ when on placebo, but only $6.4 \%$ when on vitamin $\mathrm{C}(1.5 \mathrm{~g} /$ day for 2 weeks), indicating an improvement of 6.5 percentage points (95\% CI 0.3 to $12.7 ; \mathrm{p}=0.042)$ for vitamin C. With the conservative imputation of the "no vitamin $\mathrm{C}$ effect' for nine participants in the Cohen et $a l^{21}$ study, there was a reduction in the postexercise $\mathrm{FEV}_{1}$ decline by 11.2 percentage points $(95 \%$ CI 4.8 to $17.6 ; \mathrm{p}=0.002)$ on the vitamin $\mathrm{C}$ day ( $2 \mathrm{~g}$ single dose).

EIB is not a dichotomous condition; instead, there is a continuous variation in the possible level of $\mathrm{FEV}_{1}$ decline caused by exercise. A single constant percentage point estimate of the vitamin $\mathrm{C}$ effect for all people who suffer from EIB may thus be simplistic. Instead, it is possible that a relative scale would better capture the effect of vitamin C. Schachter and Schlesinger ${ }^{20}$ published individual-level data for all their 12 participants, and thus their data were analysed using linear modelling to examine whether the vitamin $\mathrm{C}$ effect might depend on the placebo-day postexercise $\mathrm{FEV}_{1}$ decline, that is, on the baseline severity of EIB (figure 2). Adding the placebo-day postexercise $\mathrm{FEV}_{1}$ decline values to the null linear model, which is equivalent to the $\mathrm{t}$ test, improved the model fit by $\chi^{2}(1 \mathrm{df})=16.5$, corresponding to $\mathrm{p}<0.001$. This indicates that the linear model that includes the placebo-day postexercise $\mathrm{FEV}_{1}$ decline explains the effect of vitamin $C$ much better than the constant 7.4 percentage point effect for all their participants suffering from EIB. The slope of the linear model indicates a $55 \%$ reduction in the decline of the postexercise $\mathrm{FEV}_{1}(95 \%$ CI $32 \%$ to $78 \%$; $\mathrm{p}<0.001)$ for vitamin $\mathrm{C}$ administration compared with placebo. Thus, in the percentage points scale, though there was a trend towards a mean vitamin $\mathrm{C}$ effect, the difference between vitamin $\mathrm{C}$ and placebo in the Schachter and Schlesinger trial was not significant $(\mathrm{p}=0.054)$, whereas in the linear model 


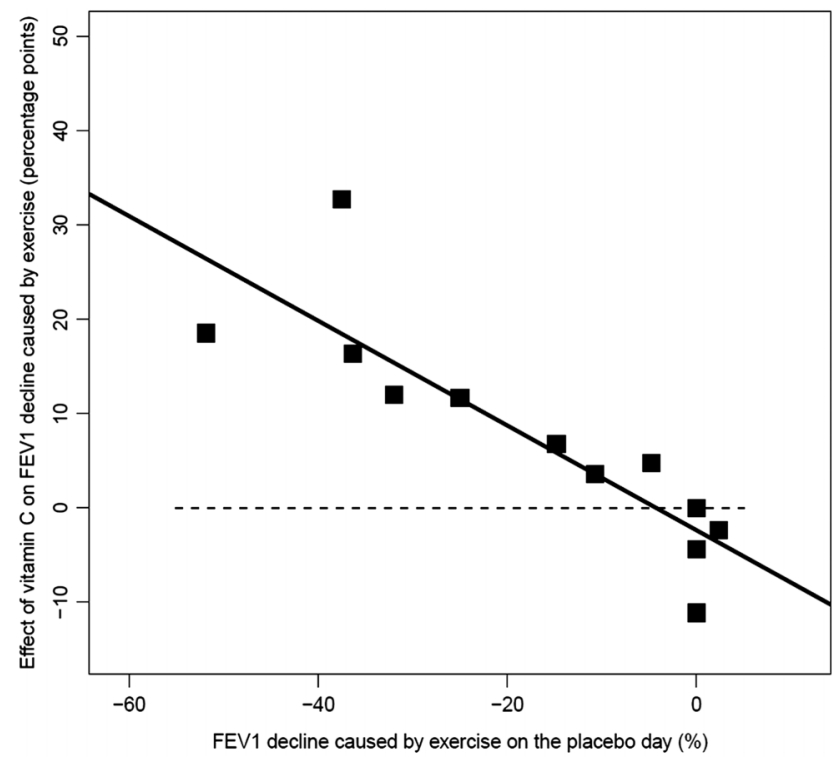

Figure 2 The effect of vitamin $\mathrm{C}$ on postexercise forced expiratory volume in $1 \mathrm{~s}\left(\mathrm{FEV}_{1}\right)$ decline as a function of the placebo-day postexercise $\mathrm{FEV}_{1}$ decline for the Schachter and Schlesinger study. ${ }^{20}$ The squares show the 12 participants of the study. The vertical axis shows the difference in postexercise $\mathrm{FEV}_{1}$ decline between the vitamin $\mathrm{C}$ and the placebo days. The horizontal axis shows the postexercise $\mathrm{FEV}_{1}$ decline on the placebo day. The black line indicates the fitted linear regression line. The horizontal dash (-) line indicates the level of identity between vitamin $C$ and placebo. See online supplementary file 2 for the calculations.

the slope indicates a highly significant difference between vitamin $\mathrm{C}$ and placebo $(\mathrm{p}<0.001)$.

Cohen et $a l^{21}$ published individual-level data for only 11 of their 20 participants (filled squares in figure 3). A conservative 'no vitamin C effect' was imputed for the remaining nine participants (open squares in figure 3). Only those participants who had a decline in postexercise $\mathrm{FEV}_{1}$ of at least $15 \%$ were included in the Cohen et al study, and therefore the horizontal variation in the Cohen et al data was narrow. Fitting the linear regression line through the origin indicates a $42 \%$ reduction in the postexercise $\mathrm{FEV}_{1}$ decline (95\% CI $19 \%$ to $64 \%$ ) with vitamin $\mathrm{C}$ administration.

Tecklenburg et $a l^{11}$ did not report individual-level data for their eight participants and the data were not available. The mean values indicate a $50.4 \%$ (95\% CI $2.4 \%$ to $98 \%$ ) reduction in the postexercise $\mathrm{FEV}_{1}$ decline for the vitamin $\mathrm{C}$ period.

There was no statistical heterogeneity found between the three studies on the relative effect scale: $\mathrm{I}^{2}=0 \% ; \chi^{2}$ $(2 \mathrm{df})=0.7 ; \mathrm{p}=0.7$. Therefore, the pooled estimate of the relative vitamin $\mathrm{C}$ effect was calculated for the three trials (figure 4). Compared with the placebo phases, vitamin $\mathrm{C}$ administration reduced the postexercise $\mathrm{FEV}_{1}$ decline by $48 \%$ (95\% CI $33 \%$ to $64 \%$; $<<0.001)$.

As a sensitivity test, the Cohen et al study was excluded from the meta-analysis in figure 1 . On the basis of the

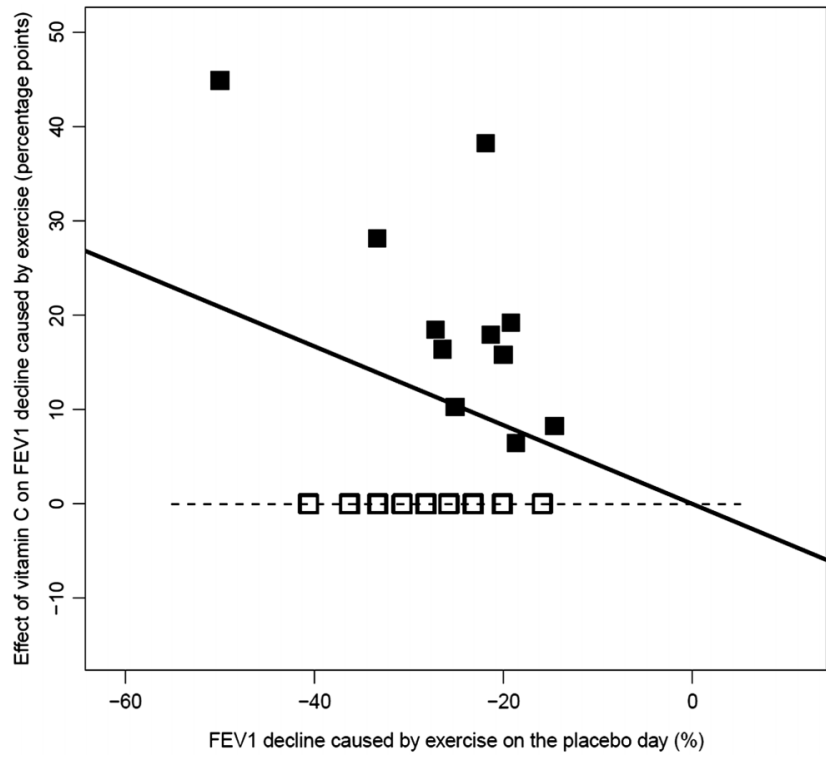

Figure 3 The effect of vitamin $\mathrm{C}$ on postexercise forced expiratory volume in $1 \mathrm{~s}\left(\mathrm{FEV}_{1}\right)$ decline as a function of the placebo-day postexercise $\mathrm{FEV}_{1}$ decline for the Cohen et $\mathrm{al}^{21}$ study. The filled squares show the 11 participants for whom data were reported and the empty squares show the nine participants for whom the conservative 'no vitamin C effect' data were imputed. The vertical axis shows the difference in the postexercise $\mathrm{FEV}_{1}$ decline between the vitamin $\mathrm{C}$ and the placebo days. The horizontal axis shows the postexercise $\mathrm{FEV}_{1}$ decline on the placebo day. The black line indicates the fitted linear regression line. The horizontal dash (-) line indicates the level of identity between vitamin $C$ and placebo. The linear regression line was fitted through the origin, since the variation in the placebo-day $\mathrm{FEV}_{1}$ decline values is narrow. See online supplementary file 2 for the calculations.

two remaining trials, the estimate of the vitamin $\mathrm{C}$ effect on the postexercise $\mathrm{FEV}_{1}$ decline became 6.8 percentage points $(95 \%$ CI 2.0 to $11.6 ; \mathrm{p}=0.005)$. Thus, the Cohen et al study imputations are not crucial for the conclusion that vitamin $\mathrm{C}$ influences the postexercise $\mathrm{FEV}_{1}$ decline.

Finally, although Cohen et al did not report individuallevel data for the postexercise $\mathrm{FEV}_{1}$ decline values for nine of their participants, they reported the presence or absence of EIB (at least a $15 \%$ decline in postexercise $\mathrm{FEV}_{1}$ ) on the vitamin $\mathrm{C}$ and placebo days and this dichotomised $\mathrm{FEV}_{1}$ outcome does not suffer from missing data. On the placebo day, $100 \%(20 / 20)$ of participants suffered from EIB, whereas on the vitamin $\mathrm{C}$ day, only $50 \%(10 / 20)$ suffered from EIB. This outcome gives a 50 percentage point decrease $(95 \%$ CI 23 to 68; $\mathrm{p}<0.001)$ in the occurrence of EIB following vitamin $\mathrm{C}$ administration.

\section{DISCUSSION}

In this meta-analysis of three randomised placebocontrolled double-blind trials, vitamin $\mathrm{C}$ was found to reduce the postexercise decline in $\mathrm{FEV}_{1}$ by a mean of 8.4 percentage points (figure 1). Nevertheless, there is a 
Study

Tecklenburg 2007
Schachter 1982
Cohen 1997

Fixed effect model
TE SeTE

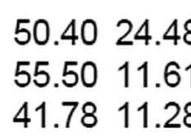

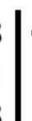

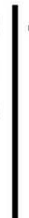

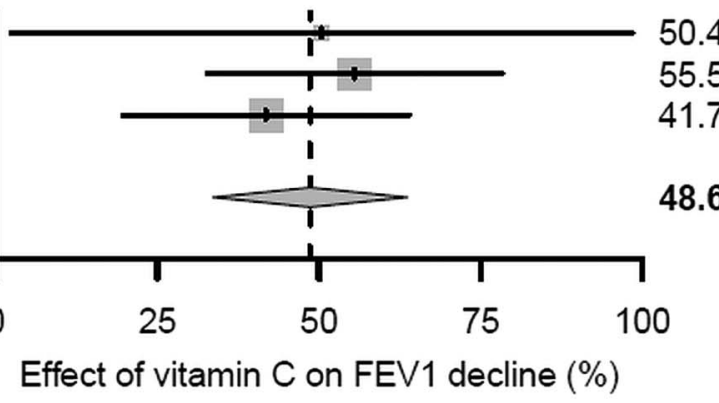

$95 \%-\mathrm{Cl}$ W(fixed)

Figure 4 Relative effect of vitamin $\mathrm{C}$ on the decline in $\mathrm{FEV}{ }_{1}$ caused by exercise. The horizontal lines indicate the $95 \% \mathrm{Cl}$ for the three trials and the squares in the middle of the lines indicate the mean effect of the study. The diamond shape at the bottom indicates the $95 \% \mathrm{Cl}$ for the pooled effect. The estimates for the Schachter 1982 and Cohen 1997 studies are based on the slopes of the linear models in figures 3 and 4 . The estimates for the Tecklenburg 2007 study are the study mean estimates. FEV $_{1}$, forced expiratory volume in $1 \mathrm{~s}$; seTE, SE of TE; TE, treatment effect; W, weight of the study.

great variation in the level of $\mathrm{FEV}_{1}$ decline caused by exercise. Therefore, it may not be reasonable to assume that a single and constant percentage point estimate of the vitamin $\mathrm{C}$ effect is valid for all persons suffering from EIB. Linear modelling of the Schachter and Schlesinger ${ }^{20}$ data indicated that it is much better to study the response to vitamin $\mathrm{C}$ administration as a relative effect (figure 2). However, full individual-level data were not available for the other two trials. Nonetheless, all three studies are consistent with vitamin $\mathrm{C}$ administration halving the postexercise decline in $\mathrm{FEV}_{1}$ (figure 4).

The Cohen $e t a l^{21}$ study required imputations for nine participants; however, excluding the Cohen et al study from the percentage point meta-analysis did not influence conclusions. Furthermore, Cohen et al reported that the number of participants who suffered from EIB dropped from $100 \%$ on the placebo day to $50 \%$ on the vitamin $\mathrm{C}$ day and this outcome did not require imputations; yet the highly significant benefit of vitamin $\mathrm{C}$ was also seen in this outcome.

The three studies included in this systematic review indicate that $0.5-2 \mathrm{~g}$ of vitamin $\mathrm{C}$ administration before exercise may have a beneficial effect on many people suffering from EIB. All the three trials were double-blind placebo-controlled randomised trials. The total number of participants in the three trials is only 40 . However, the three trials were carried out in three different decades and on two different continents. The criteria for EIB differed and the mean age of the participants was 14 years in the Cohen et al study but 25 and 26 years in the two other studies. Still, all the studies found a $50 \%$ reduction in the postexercise $\mathrm{FEV}_{1}$ decline. It is not evident how far this $50 \%$ estimate can be generalised, but the close estimate in such different studies suggests that the estimate may also be valid for several other people who suffer from EIB.

The search, screening and selection for trials and data extraction were carried out by one person, which may be considered a limitation of this study. In addition, only two databases were searched; however, in an independent literature search, the Cochrane review on vitamin $\mathrm{C}$ and asthma did not identify more trials on vitamin $\mathrm{C}$ and EIB. ${ }^{18}$ Data analysis was also performed by one person, but the supplementary files show the extracted data and data analyses, which makes the study transparent. No risk of bias or quality assessment was performed as part of this study.

In evidence-based medicine, the primary question is whether an intervention has effects on clinically relevant outcomes, as well as on symptoms such as coughs. With such a perspective, the aetiology of respiratory symptoms is not of prime importance. Given the low cost and safety of vitamin $\mathrm{C},{ }^{15}{ }^{28}$ and the consistency of positive findings in the three studies on EIB, it seems reasonable for physically fit and active people to test vitamin $\mathrm{C}$ on an individual basis if they have respiratory symptoms such as cough associated with exercise.

The promising results of EIB and common cold studies indicate that further research on vitamin $\mathrm{C}$ and the respiratory symptoms of physically active people are warranted. In future trials, statistical modelling should be used to examine the effect of vitamin $\mathrm{C}$ on $\mathrm{FEV}_{1}$ levels, instead of simply calculating the percentage point estimates. Although the primary question in the evidence-based medicine framework is to assess the effectiveness of vitamin $\mathrm{C}$ on clinically relevant outcomes, the aetiology of the respiratory symptoms should also be investigated in future investigations.

Acknowledgements The author would like to thank Dr Tecklenburg who kindly supplied supplementary data for this analysis and Elizabeth Stovold for her contributions to an early version of this manuscript, by helping in the literature searches, considering studies for inclusion and extracting data for the meta-analysis.

Funding This research received no specific grant from any funding agency in the public, commercial or not-for-profit sectors.

Competing interests None.

Provenance and peer review Not commissioned; externally peer reviewed. 
Data sharing statement All collected and imputed data are presented in online supplementary files 2 and 3 and are freely available.

\section{REFERENCES}

1. Weiler JM, Anderson SD, Randolph C. Pathogenesis, prevalence, diagnosis, and management of exercise-induced bronchoconstriction. Ann Allergy Asthma Immunol 2010;105(6 Suppl):S1-47.

2. Anderson SD, Kippelen P. Airway injury as a mechanism for exercise-induced bronchoconstriction in elite athletes. J Allergy Clin Immunol 2008;122:225-35.

3. Buchvald F, Hermansen MN, Nielsen KG, et al. Exhaled nitric oxide predicts exercise-induced bronchoconstriction in asthmatic school children. Chest 2005;128:1964-7.

4. Puglisi L, Berti F, Bosisio E, et al. Ascorbic acid and PGF2 $\alpha$ antagonism on tracheal smooth muscle. Adv Prostaglandin Thromboxane Res 1976;1:503-6.

5. Rothberg KG, Hitchcock M. Effects of ascorbic acid deficiency on the in vitro biosynthesis of cyclooxygenase metabolites in guinea pig lungs. Prostaglandins Leukot Med 1983;12:137-47.

6. Mohsenin V, Tremml PG, Rothberg KG, et al. Airway responsiveness and prostaglandin generation in scorbutic guinea pigs. Prostaglandins Leukot Essent Fatty Acids 1988;33:149-55.

7. Zuskin E, Lewis AJ, Bouhuys A. Inhibition of histamine-induced airway constriction by ascorbic acid. J Allergy Clin Immunol 1973;51:218-26.

8. Sipahi E, Ercan ZS. The mechanism of the relaxing effect of ascorbic acid in guinea pig isolated tracheal muscle. Gen Pharmacol 1997;28:757-60.

9. Ogilvy CS, DuBois AB, Douglas JS. Effects of ascorbic acid and indomethacin on the airways of healthy male subjects with and without induced bronchoconstriction. J Allergy Clin Immunol 1981;67:363-9.

10. Mohsenin V, Dubois AB, Douglas JS. Effect of ascorbic acid on response to methacholine challenge in asthmatic subjects. Am Rev Respir Dis 1983;127:143-7.

11. Tecklenburg SL, Mickleborough TD, Fly AD, et al. Ascorbic acid supplementation attenuates exercise-induced bronchoconstriction in patients with asthma. Respir Med 2007;101:1770-8.

12. Powers SK, Jackson MJ. Exercise-induced oxidative stress: cellular mechanisms and impact on muscle force production. Physiol Rev 2008;88:1243-76.
13. Ashton T, Young IS, Peters JR, et al. Electron spin resonance spectroscopy, exercise, and oxidative stress: an ascorbic acid intervention study. J Appl Physiol 1999;87:2032-6. http://www.ncbi. nlm.nih.gov/pubmed/10601146

14. Hemilä $\mathrm{H}$. Vitamin $\mathrm{C}$ and common cold incidence: a review of studies with subjects under heavy physical stress. Int J Sports Med 1996;17: 379-83. http://hdl.handle.net/10250/7983 (accessed 7 May 2013)

15. Hemilä $\mathrm{H}$, Chalker $\mathrm{E}$. Vitamin $\mathrm{C}$ for preventing and treating the common cold. Cochrane Database Syst Rev 2013;(1):CD000980.

16. Hemilä $\mathrm{H}$. Vitamin $\mathrm{C}$ supplementation and common cold symptoms: problems with inaccurate reviews. Nutrition 1996;12:804-9. http:// hdl.handle.net/10250/7979 (accessed 7 May 2013)

17. Hemilä $\mathrm{H}$, Louhiala $\mathrm{P}$. Vitamin $\mathrm{C}$ may affect lung infections. $J R$ Soc Med 2007;100:495-8.

18. Kaur B, Rowe BH, Stovold E. Vitamin C supplementation for asthma Cochrane Database Syst Rev 2009;(1):CD000993.

19. Hemilä H. Feedback. In: Kaur B, Rowe BH, Stovold E. Vitamin C supplementation for asthma. Cochrane Database Syst Rev 2009;(1): CD000993. http://hdl.handle.net/10138/38500 (accessed 7 May 2013)

20. Schachter EN, Schlesinger A. The attenuation of exercise-induced bronchospasm by ascorbic acid. Ann Allergy 1982;49:146-51. http:// www.ncbi.nlm.nih.gov/pubmed/7114587

21. Cohen HA, Neuman I, Nahum $\mathrm{H}$. Blocking effect of vitamin $\mathrm{C}$ in exercise-induced asthma. Arch Pediatr Adolesc Med 1997;151:367-70.

22. Miric M, Haxhiu MA. Effect of vitamin C on exercise-induced bronchoconstriction [Serbo-Croatian]. Plucne Bolesti 1991;43:94-7. http://www.ncbi.nlm.nih.gov/pubmed/1766998

23. Murphy JD, Ferguson CS, Brown KR, et al. The effect of dietary antioxidants on lung function in exercise induced asthma [abstract] Med Sci Sports Exerc 2002;34(5 Suppl):S155.

24. Higgins JPT, Thompson SG, Deeks JJ, et al. Measuring inconsistency in meta-analysis. BMJ 2003;327:557-60.

25. The R Project for Statistical Computing. http://www.r-project.org/ (accessed 7 May 2013)

26. Lydersen S, Fagerland MW, Laake P. Recommended tests for association in $2 \times 2$ tables. Stat Med 2009;28:1159-75. http://www. ncbi.nlm.nih.gov/pubmed/19170020

27. Fagerland MW, Lydersen S, Laake P. Recommended confidence intervals for two independent binomial proportions. Stat Methods Med Res 2011. Published Online First 2011. doi:10.1177/ 0962280211415469

28. Hathcock JN, Azzi A, Blumberg J, et al. Vitamins E and C are safe across a broad range of intakes. Am J Clin Nutr 2005;81:736-45. 